\title{
Total Body Electrical Conductivity Used to Determine Body Composition in Infants ${ }^{1}$
}

\author{
WILLIAM J. COCHRAN, WILLIAM J. KLISH, WILLIAM W. WONG, AND PETER D. KLEIN \\ USDA/ARS Children's Nutrition Research Center, Department of Pediatrics, Baylor College of Medicine and \\ Texas Children's Hospital, Houston, Texas 77030
}

\begin{abstract}
Total body electrical conductivity (TOBEC) has been introduced as a rapid, safe, and noninvasive method suitable for the estimation of fat-free mass. The instrument (EMME or TOBEC) operates on the principle that organisms placed in an electromagnetic field perturb the field to a degree that depends on the amount and volume of distribution of electrolytes present. A study was designed to measure body composition in infants by the TOBEC method and to compare the results with those obtained using the isotope dilution technique. Sixteen infants (age range, 2 days to 9.7 months; weight range, 2 to $8.7 \mathrm{~kg}$ ) were enrolled. Total body water (TBW) was determined by the isotope dilution technique using $\mathrm{H}_{2}{ }^{18} \mathrm{O}$. There was a good correlation between the natural logarithm of the TOBEC number and TBW, with a linear correlation coefficient of 0.949 . The fat-free body mass of the infants was calculated by TBW (fat-free body mass $=/ 0.082$ ) and by the TOBEC method using the standard previously derived from mature rabbits. TBW measurements by $\mathrm{H}_{2}{ }^{18} \mathrm{O}$ dilution appeared to overestimate fat-free mass which was greater than $T B W$ in five of the 16 infants. Measured by the TOBEC method, fat-free mass ranged from 51 to $91 \%$ of total body weight. The TOBEC method is highly suitable for use with human infants and appears to determine body composition as accurately as other available methods. (Pediatr Res 20: 561-564, 1986)
\end{abstract}

\section{Abbreviations}

TBW, total body water

TOBEC, total body electrical conductivity

FFM, fat-free body mass

Total body electrical conductivity has been described as a rapid, safe, and noninvasive method suitable for the determination of FFM in infants (1). The TOBEC methodology is based on the principle that organisms placed in an electromagentic field perturb the field. The degree of perturbation is dependent on the amount and volume of distribution of electrolytes present. Our initial calibration studies revealed that the TOBEC signal is

Received November 13, 1985; accepted February 14, 1986

Correspondece and requests for reprints to William J. Cochran, M.D., Medical Towers Bldg., 6608 Fannin, Suite 601, Houston, TX 77030.

This work is a publication of the USDA/ARS Children's Nutrition Research Center, Department of Pediatrics, Baylor College of Medicine and Texas Children's Hospital. This project has been funded in part with federal funds from the U.S Department of Agriculture, Agricultural Research Service under Cooperative Agreement number 58-7MNI-6-100 and is also supported in part by NIH Grant 7R01 HD 18896-01.

${ }^{1}$ The contents of this publication do not necessarily reflect the views or policies of the U.S. Department of Agriculture, nor does mention of trade names, commercial products, or organizations imply endorsement by the U.S. Government. affected by the shape, temperature, and movement of the object, as well as by the position of the object on the carriage. The signal also is affected by the absolute amount, composition, and concentration of the electrolytes present (1). When there is a simultaneous increase in both the quantity of electrolytes and the volume of their distribution, but no change in concentration, the TOBEC number increases exponentially. When the TOBEC number is expressed as the natural logarithm, the increase becomes linear. An increase in the temperature of an object increases the TOBEC number, although no significant change occurs within the physiologic range of temperatures. Good linear correlation has been demonstrated between the natural log of the TOBEC number and FFM for phantom infants $(r=0.98)$, ground beef $(r=0.91)$, and live rabbits $(r=0.99)(1)$.

Van Itallie and coworkers $(2,3)$ have applied this methodology to estimate body composition in adults. They found good correlation between the TOBEC measurement and TBW $(r=0.87)$, total body potassium $(r=0.86)$, and hydrostatically estimated FFM $(r=0.943)$.

This report describes the use of the TOBEC method to determine body composition in human infants and compares the results with those obtained using the isotope dilution technique.

\section{MATERIALS AND METHODS}

Sixteen healthy human infants were enrolled in the study and informed consent was obtained from their parents. The protocol and consent form were reviewed and approved by the Institutional Review Boards for Human Research of Baylor College of Medicine and Texas Children's Hospital.

The infants ranged in age from 2 days to 9.7 months and their weights ranged from 2 to $8.7 \mathrm{~kg}$. Nine male and seven female infants were studied.

At the onset of the study, each infant was weighed naked on an electronic scale (Sartorius $3804 \mathrm{MP}$ ) which has a precision of $\pm 0.05 \mathrm{~g}$. Triceps and subscapular skinfold thicknesses also were determined in the usual manner using Lange calipers.

Each infant was dressed and swaddled prior to the TOBEC measurement. All infants were placed in the same position on the carriage to minimize the effect of position on the TOBEC signal (1). Each infant was measured 10 times in the TOBEC instrument (model M-60, DICKEY-john, Auburn, IL) and the measurements were averaged. Because the movement of the infant affected the signal, each infant was observed during the measurements. If the infant moved, the measurement was disregarded and another obtained.

The stability of the instrument was determined by a daily measurement of a standard which consisted of several loops of copper wire in series with a transistor housed in a plastic box. The average TOBEC number generated from this standard was $217.7 \mathrm{U}$ with a SD of 3.30 .

FFM was calculated by comparing the TOBEC number to the standard curve derived from carcass analyses of mature rabbits 
(1). The regression line of that curve is $\mathrm{Y}=0.44 \mathrm{X}+3.97$ where $\mathrm{Y}$ is the natural logarithm of the TOBEC number and $\mathrm{X}$ is the FFM. Expressed in terms of fat-free mass:

$$
\mathrm{X}=\frac{\mathrm{Y}-3.97}{0.44}, \mathrm{~kg}
$$

Immediately after the TOBEC measurement, TBW was determined by standard dilutional techniques using water labeled with the stable isotope oxygen-18 (4). A baseline urine sample was obtained using a urine collection bag. The infant then was given $\mathrm{H}_{2}{ }^{18} \mathrm{O}$ at a dose of $60 \mathrm{mg}$ isotope $/ \mathrm{kg}$. The $\mathrm{H}_{2}{ }^{18} \mathrm{O}$ was delivered into the oropharynx with a syringe which was weighed before and after to determine the amount of isotope administered. A postdose urine sample was collected after $4 \mathrm{~h}$; samples collected before $4 \mathrm{~h}$ were discarded. The ${ }^{18} \mathrm{O} /{ }^{16} \mathrm{O}$ ratios in the urine samples were determined using the Aqua-SIRA mass spectrometer system (VG Isogas Ltd., Cheshire, England) described by Wong et al. (5). The oxygen-18 measurements for infants $6-8,10$, and $12-$ 16 were made after equilibration with $\mathrm{CO}_{2}$ according to the method described by Schoeller et al. (4).

TBW was calculated from the following formula:

$$
\mathrm{TBW}=\frac{\text { dose }}{\mathrm{MW}} \times \frac{\mathrm{APE}}{100} \times 18.02 \times \frac{1}{\mathrm{R}_{\mathrm{std}} \times \Delta \mathrm{I}_{\text {so }}}, \mathrm{kg}
$$

where MW is the molecular weight of the isotopic water, APE is atom percentage enrichment of the isotope, $R_{\text {std }}$ is the isotopic ratio in the standard, and $I_{s o}$ is the arithmetic difference in isotope enrichment in urine before and after isotope administration.

FFM was calculated from the TBW measurement using the following equation:

$$
\mathrm{FFM}=\frac{\mathrm{TBW}}{0.820}, \mathrm{~kg}
$$

The term 0.820 was the value used by Widdowson (6) for the water content of $1 \mathrm{~kg}$ of FFM of a full-term infant.

\section{RESULTS}

The anthropometric data obtained are shown in Table 1. The triceps skinfold thicknesses ranged from 2.8 to $11 \mathrm{~mm}$. All the triceps skinfold thickness measurements were within the published normal range (7). The subscapular skinfold thickness measurements had the same range as those of the triceps skinfold thickness and were similar in any given subject.

The TOBEC determinations are presented in Table 2. The average TOBEC number for each infant ranged from 112 to 390 with SD of 4.6 to 8.4 TOBEC units. FFM determined by the

Table 1. Anthropometric data

\begin{tabular}{clrrcc}
\hline & & $\begin{array}{c}\text { Age } \\
\text { Infant }\end{array}$ & $\begin{array}{c}\text { Wt } \\
(\text { day })\end{array}$ & $\begin{array}{c}\text { Triceps skinfold } \\
(\mathrm{mm})\end{array}$ & $\begin{array}{c}\text { Subscapular skinfold } \\
(\mathrm{mm})\end{array}$ \\
\hline 1 & M & 2 & 2.740 & 4 & 4 \\
2 & F & 2 & 2.580 & 5 & 5.2 \\
3 & M & 3 & 2.010 & 3 & 3 \\
4 & M & 3 & 2.010 & 2.8 & 2.8 \\
5 & M & 30 & 2.940 & $*$ & $*$ \\
6 & F & 38 & 4.090 & 6 & 6 \\
7 & M & 45 & 3.160 & 4 & 4 \\
8 & F & 60 & 4.200 & 6 & 6 \\
9 & F & 75 & 5.080 & 8 & 4 \\
10 & M & 75 & 4.455 & 3.5 & $*$ \\
11 & F & 120 & 4.860 & $*$ & 11 \\
12 & M & 120 & 6.920 & 10 & 5 \\
13 & F & 135 & 6.790 & 6 & $*$ \\
14 & F & 150 & 5.100 & 6 & 11 \\
15 & M & 195 & 7.760 & $*$ & \\
16 & M & 291 & 8.773 & 11 & \\
\hline
\end{tabular}

* Data not obtained.
Table 2. TOBEC determinations

\begin{tabular}{ccccc}
\hline \multicolumn{5}{c}{ Table 2. TOBEC } \\
Infant & In TOBEC no. & $\begin{array}{c}\text { Absolute wt } \\
(\mathrm{kg})\end{array}$ & $\begin{array}{c}\text { FFM* } \\
(\mathrm{kg})\end{array}$ & \% FFM \\
\hline 1 & 5.0645 & 2.740 & 2.488 & 90.8 \\
2 & 4.7510 & 2.580 & 1.775 & 68.8 \\
3 & 4.6923 & 2.010 & 1.642 & 81.7 \\
4 & 4.7185 & 2.010 & 1.701 & 84.6 \\
5 & 5.0206 & 2.940 & 2.388 & 81.2 \\
6 & 5.4337 & 4.090 & 3.327 & 81.3 \\
7 & 5.1846 & 3.160 & 2.760 & 87.3 \\
8 & 5.3863 & 4.200 & 3.203 & 76.3 \\
9 & 5.4201 & 5.080 & 3.296 & 64.9 \\
10 & 5.4773 & 4.455 & 3.426 & 76.9 \\
11 & 5.3678 & 4.860 & 3.177 & 65.4 \\
12 & 5.8239 & 6.920 & 4.213 & 60.9 \\
13 & 5.8545 & 6.790 & 4.283 & 63.1 \\
14 & 5.6462 & 5.100 & 3.810 & 74.7 \\
15 & 5.9564 & 7.760 & 4.515 & 58.2 \\
16 & 5.9661 & 8.773 & 4.537 & 51.7 \\
\hline
\end{tabular}

${ }^{*} \mathrm{FFM}=\frac{(\ln \text { TOBEC number }-3.97)}{0.44}$.

TOBEC method using equation 1 ranged from 1.642 to 4.537 $\mathrm{kg}$. The range in percent weight as FFM was unexpectedly large and varied from 51.7 to $90.8 \%$. There was a general tendency for the percent weight as FFM to decrease as age and body weight increased.

The relationship between the percent body weight as fat determined by the TOBEC method and the natural logarithm of the sum of the triceps and subscapular skinfold thicknesses is depicted in Figure 1. A significant relationship is noted with a linear correlation coefficient of 0.817 .

The TBW measurements determined by the dilution technique are shown in Table 3 . The TBW measurements ranged from 1.563 to $5.737 \mathrm{~kg}$. The percent body weight as TBW ranged from 57.7 to $88.0 \%$. When the TBW measurements using $\mathrm{H}_{2}{ }^{18} \mathrm{O}$ were plotted against the natural logarithm of the TOBEC number (Fig. 2), a significant linear correlation was obtained $(r=0.949)$.

Values for FFM as calculated from the TBW measurements using equation 3 are shown in Table 3. FFM ranged from 1.907 to $6.659 \mathrm{~kg}$. The percent body weight as FFM ranged from 70.4 to $107.4 \%$. Five of the 16 values were greater than $100 \%$.

The relationship between FFM determined by the TOBEC method and FFM calculated from TBW is shown in Figure 3. Unlike the linear relationship between the natural logarithm of the TOBEC number and TBW measured with $\mathrm{H}_{2}{ }^{18} \mathrm{O}$, the relationship between FFM determined by the TOBEC method and FFM calculated from TBW was not linear. Linearity extended to approximately $4 \mathrm{~kg}$ of FFM; above $4 \mathrm{~kg}$ the relationship became curvilinear. The logarithmic function, $\mathrm{Y}=2.62(\ln \mathrm{X})$ $-0.0736 \mathrm{X}-0.0645$, where $\mathrm{X}$ is the FFM determined by TOBEC and $Y$ is the FFM determined by TBW, fit the data better than the linear regression equation ( $r=0.94$ versus 0.96$)$. As seen in Figure 3 , all points lie above the line of identity indicating that FFM calculated from TBW was greater than FFM calculated by the TOBEC method.

\section{DISCUSSION}

There are few reports in the literature on infant growth composition (accretion of fat versus FFM). The paucity of knowledge is due to the difficulties encountered when the available techniques are applied to this population. The TOBEC method was developed for other purposes, but has been used successfully to determine FFM in human adults $(2,3)$. The results of our study show that the method can be used successfully in human infants as well.

Anthropometric measurements have been used as the classic determinants of body composition in infants. The method is 


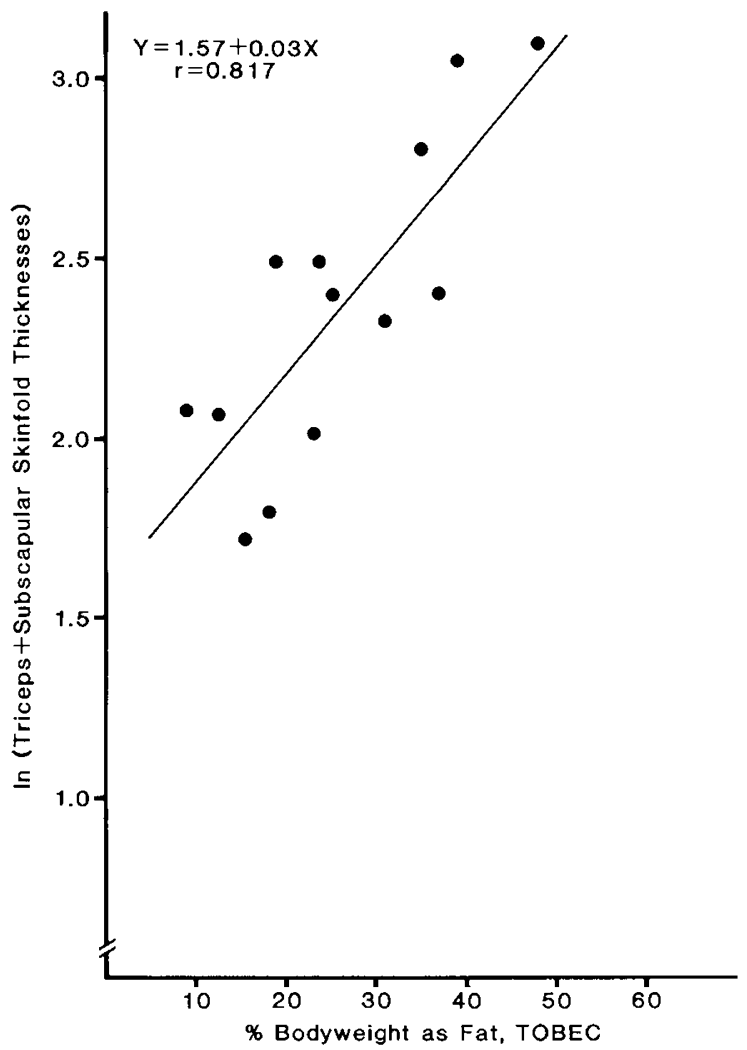

Fig. 1. Comparison of the natural $\log$ of the sum of the triceps and subscapular skinfold thicknesses to percent body weight as fat as determined using the TOBEC method. Linear regression analysis noted on figure. The SE of the estimate is 0.26 .

Table 3. Estimated TBW and FFM based on the dilution of $\mathrm{H}_{2}{ }^{18} \mathrm{O}$

\begin{tabular}{ccccr}
\hline Infant & TBW $(\mathrm{kg})$ & $\%$ TBW & FFM $(\mathrm{kg})$ & \% FFM \\
\hline 1 & 2.173 & 79.3 & 2.650 & 96.7 \\
2 & 1.879 & 72.8 & 2.291 & 88.8 \\
3 & 1.769 & 88.0 & 2.158 & 107.4 \\
4 & 1.563 & 77.3 & 1.907 & 94.9 \\
5 & 2.554 & 86.9 & 3.115 & 106.0 \\
6 & 3.566 & 87.3 & 4.354 & 106.4 \\
7 & 2.728 & 86.4 & 3.329 & 105.4 \\
8 & 3.185 & 75.7 & 3.878 & 92.3 \\
9 & 2.931 & 57.7 & 3.575 & 70.4 \\
10 & 3.521 & 79.0 & 4.293 & 96.4 \\
11 & 3.869 & 75.9 & 4.499 & 92.6 \\
12 & 5.322 & 76.9 & 6.488 & 93.8 \\
13 & 5.737 & 84.5 & 7.000 & 103.1 \\
14 & 3.733 & 73.1 & 4.549 & 89.2 \\
15 & 4.689 & 60.4 & 5.720 & 73.7 \\
16 & 5.458 & 62.2 & 6.659 & 75.9 \\
\hline
\end{tabular}

based on the assumption that the amount of subcutaneous fat is closely related to total body fat (8). Complete analysis of one full-term neonate, however, revealed that only $42 \%$ of the body fat was in subcutaneous depots (9). A linear relationship was noted in the present study between the natural logarithm of the sum of the triceps and subscapular skinfold thicknesses and the percent fat as determined by the TOBEC method. Despite a statistically significant correlation coefficient, there was great variability around the regression line. This result was not surprising, because the relationship between skinfold thicknesses and total body fat is complex.

The range in percent FFM as determined by the TOBEC method was unexpectedly large (52-91\%). The estimated percent

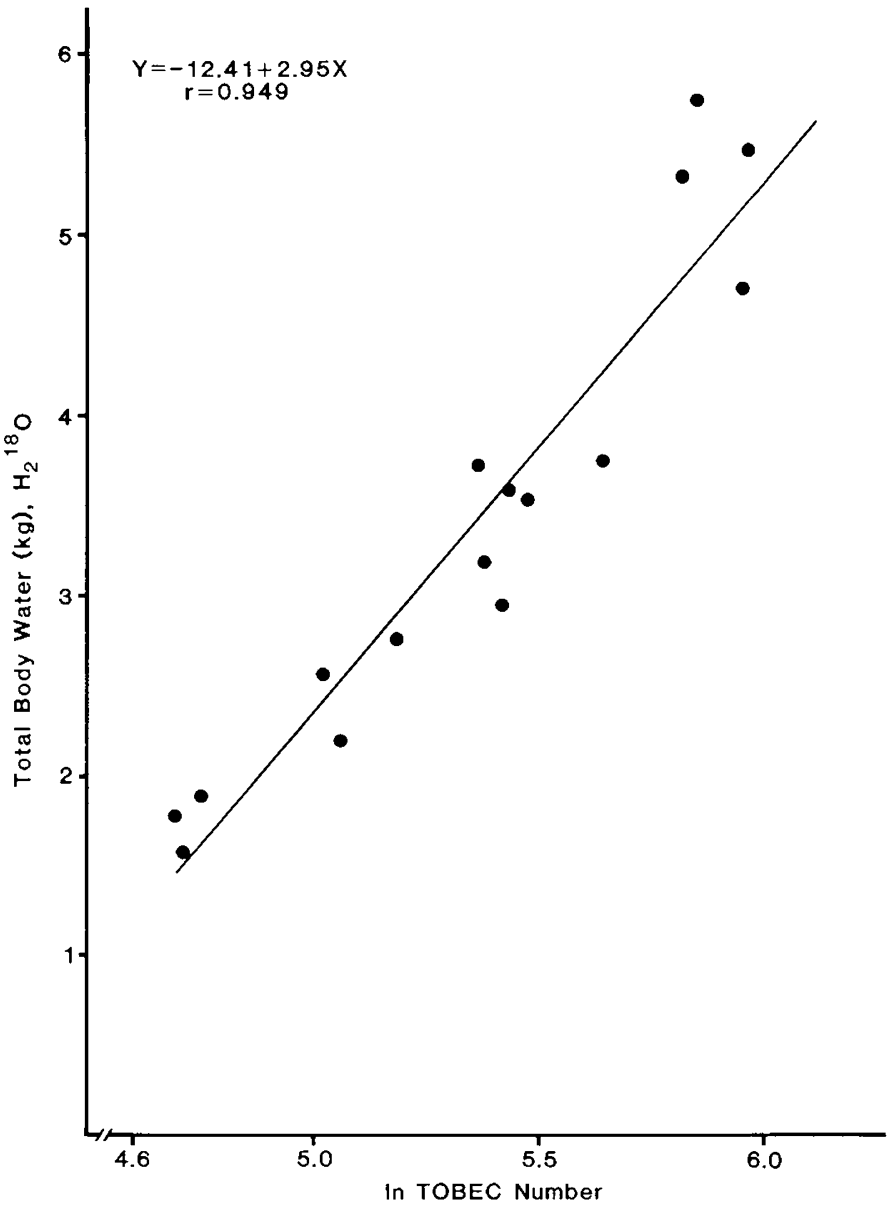

Fig. 2. Comparison of TBW value, determined by the dilution technique with $\mathrm{H}_{2}{ }^{18} \mathrm{O}$, to the natural $\log$ of the TOBEC number. Linear regression analysis noted on figure. The $\mathrm{SE}$ of the estimate is 0.44 .

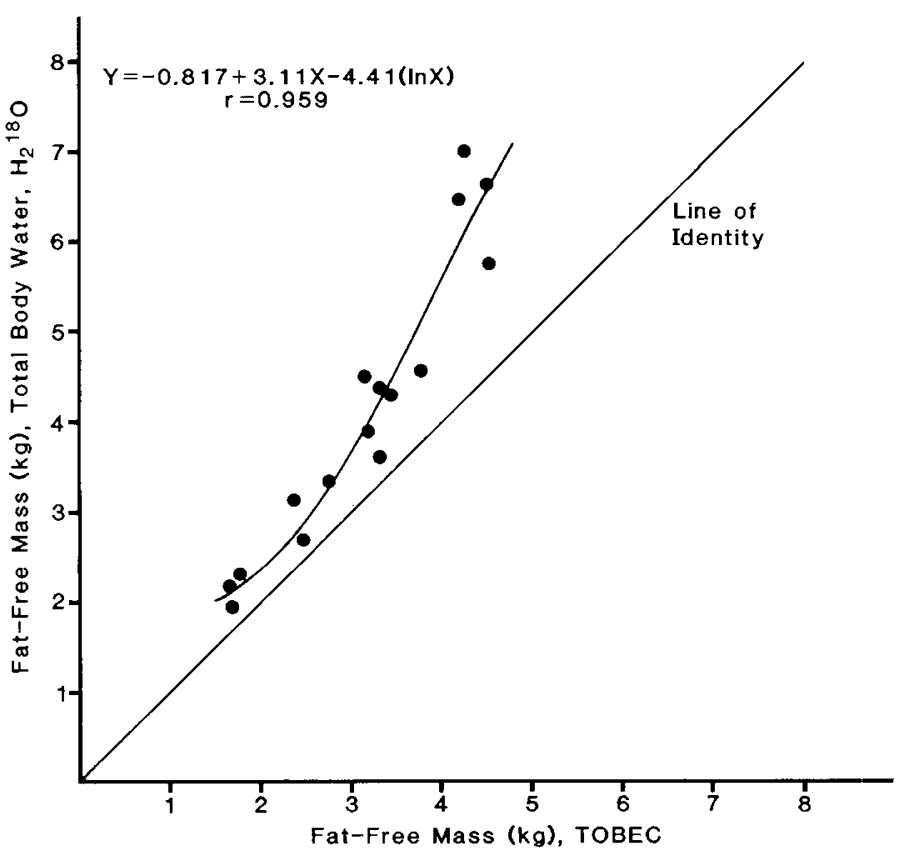

Fig. 3. Comparison of values for FFM calculated by the dilution technique and determined by the TOBEC method. The line of identity is plotted. Regression analysis is noted on figure. The SE of the estimate is 0.49 . 
FFM in most reports in the literature is between 66 and $88 \%$ $(10-12)$. The TOBEC method may have underestimated FFM because the standard used was based on the mature rabbit. This standard may be less than optimal because of changes in the water content of FFM that are known to occur with age. The mature rabbits had a water content of $732 \mathrm{ml} / \mathrm{kg}$ FFM, which is similar to that reported for adult humans. Full-term human infants, however, are reported to have a water content of 820 $\mathrm{ml} / \mathrm{kg}$ FFM (6). The TOBEC number not only is generated by the total electrolyte content of tissue but also is affected by the volume of electrolyte distribution. The water content of FFM is greater in human infants than in mature rabbits and presumably the electrolyte concentration in human infants is lower. The expectation, therefore, was that the natural logarithm of the TOBEC number might have been less per kg FFM in the infant than in the mature rabbit.

In previous studies $\mathrm{H}_{2}{ }^{18} \mathrm{O}$ has been used to determine TBW from which FFM can be calculated (4, 13). The values of percent body weight as water determined in this study by the dilution technique were similar to previously published values $(14,15)$, but greater than those for the reference child as proposed by Fomon et al. (10). There was a good correlation between the TBW measurement based on the dilution technique and the natural logarithm of the TOBEC number. This relationship raised the possibility of using the TOBEC method to determine TBW. The TOBEC method, however, does not measure water directly; no signal is generated by an analysis of distilled water. As stated earlier, the TOBEC number is generated not only by the total electrolyte content of tissue but is affected also by the volume of water in which the electrolytes are distributed. This then is the basis of the relationship between the TBW measurement and the TOBEC number. The feasibility of using the TOBEC method to measure TBW has yet to be established.

The dilution technique appeared to overestimate FFM. This overestimation was due in part to the fact that the $\mathrm{H}_{2}{ }^{18} \mathrm{O}$ dilution space may be greater than TBW. Lifson et al. (16) found that the oxygen- 18 dilution space in adult mice was $2 \%$ larger than TBW determined by desiccation. The deuterium dilution space is known to be greater than TBW in human adults and mature animals with a 2 to $5 \%$ extent of overestimation $(17,18)$. TBW may be overestimated by the dilution method in young actively growing animals by up to $15 \%$ (19). The possibility exists that the incorporation of deuterium and ${ }^{18} \mathrm{O}$ into the nonaqueous organic fraction of tissues in growing infants is more extensive than in adults. This would account for the observed overestimation of the dilution space.

Although FFM may have been underestimated by the TOBEC method in this study and overestimated by the dilution technique, a significant relationship was noted between the two values. In future studies, an infant animal standard, whose body composition more closely resembles that of the human infant, may improve the predictive accuracy of the TOBEC method, by minimizing the difference in body water content between the reference animal and human infants. Nevertheless, the TOBEC method determines body composition in infants as accurately as other methods currently in use and has the advantage of being rapid, safe, simple, and noninvasive.

Acknowledgments. The authors thank R. L. Hethcock, R.N. for assistance in recruiting and measuring the subjects, E. R. Klein for editorial review, and M. S. Perez for manuscript preparation.

\section{REFERENCES}

Y. Klish WJ, Forbes GB, Gordon A, Cochran WJ 1984 New method for the estimation of lean body mass in infants (EMME instrument): validation in nonhuman models. J Pediatr Gastroenterol Nutr 3:199-204

2. Presta E, Segal KR, Gatin B, Harrison GG, Van Itallie TB 1983 Comparison in man of total body electrical conductivity of lean body mass derived from body density: validation of a new body composition method. Metabolism 32:524-527

3. Presta E, Wong J, Harrison GG, Bjorntorp P, Harker WH, Van Itallie TB 1983 Measurement of total body electrical conductivity: a new method for estimation of body composition. Am J Clin Nutr 37:735-739

4. Schoeller DA, van Santen E, Peterson DW, Dietz W, Jaspan J, Klein PD 1980 Total body water measurement in humans with ${ }^{18} \mathrm{O}$ and ${ }^{2} \mathrm{H}$ labeled water. Am J Clin Nutr 33:2686-2693

5. Wong WW, Cabrera MP, Klein PD 1984 Evaluation of a dual mass spectrometer system for rapid simultaneous determinations of hydrogen-2/hydrogen1 and oxygen-18/oxygen-16 ratios in aqueous samples. Anal Chem 56:18521858

6. Widdowson EM 1974 Changes in body proportions and composition during growth. In: Davis JA, Dobbings $\mathrm{J}$ (eds) Scientific Foundations in Pediatrics. Wm Heinemann Medical Books, London, pp 153-163

7. Frisancho AR 1974 Triceps skinfold and upper arm muscle size norms for assessment of nutritional status. Am J Clin Nutr 27:1052-1058

8. Dauncey MJ, Gandy G, Gairdner D 1977 Assessment of total body fat in infancy from skinfold thickness measurements. Arch Dis Child 52:223-227

9. Forbes GB 1962 Methods for determining composition of the human body. With a note on the effect of diet on body composition. Pediatrics 29:477-94

10. Fomon SJ, Haschke F, Ziegler EE, Nelson SE 1982 Body composition of reference children from birth to age 10 years. Am J Clin Nutr 35:1169-1175

11. Malcom AH 1978 Body composition and energy needs during growth. In: Falkner F, Tanner JM (eds) Human Growth, Vol. 2. Plenum Publishing Corp., New York, pp 117-139

12. Snyder WS, Cook MJ, Nasset ES, Karhausen LR, Howells GP, Tipton IH (eds) 1975 Anatomical values for reference man: total body. In: Report of the Task Group on Reference Man. Pergamon Press, New York, pp 8-46

13. Trowbridge FL, Graham GG, Wong WW, Mellitis ED, Rabodd JD, Lee LS, Cabrera MP, Klein PD 1984 Body water measurements in premature and older infants using $\mathrm{H}_{2}{ }^{18} \mathrm{O}$ isotopic determinations. Pediatr Res 18:524-527

14. Friis-Hansen B 1957 Changes in body water compartments during growth Acta Paediatr 46:19-35

15. Friis-Hansen B 1983 Water distribution in the foetus and newborn infants. Acta Paediatr Scand 305:7-11

16. Lifson N, Gordon GB, McClintock R 1955 Measurement of total carbon dioxide production by means of $\mathrm{D}_{2}{ }^{18} \mathrm{O}$. J Appl Physiol 7:704-710

17. Culebras JM, Moore FD 1977 Total body water and the exchangeable hydrogen I. Theoretical calculation of nonaqueous exchangeable hydrogen in man. Am J Physiol 232:R54-R59

18. Culebras JM, Fitzpatrick GF, Brennan MF, Boyden CM, Moore FD 1977 Total body water and the exchangeable hydrogen II. A review of comparative data from animals based on isotope dilution and desiccation, with a report of new data from the rat. Am J Physiol 232:R60-R65

19. Sheng HP, Huggins RA 1979 A review of body composition studies with emphasis on total body water and fat. Am J Clin Nutr 32:630-647 